https://doi.org/10.34024/prometeica.2022.24.13312

\title{
ANDRÉS EL CAPELLÁN Y MARGARITA PORETE
}

\author{
AMOR SECULAR Y AMOR DIVINO
}

ANDREW THE CHAPLAIN AND MARGUERITE PORETE

Secular love and divine love

ANDREAS CAPELÃO E MARGUERITA PORETE

Amor secular e amor divino

\author{
Laura Carolina Durán \\ (Universidad de Buenos Aires) \\ lcarolinaduran@gmail.com \\ Recibido: 05/01/2022 \\ Aprobado: 07/01/2022
}

\begin{abstract}
RESUMEN
El presente artículo analiza aspectos centrales de las obras De amore de Andrés el Capellán y El Espejo de las almas simples de Margarita Porete. Se trata de textos que abordan la cuestión del amor, el que existe entre un hombre y una mujer y entre el alma y la divinidad, respectivamente. Ambas obras fueron condenadas por ser juzgadas heréticas. Ambos trabajos expresan el amor como un exceso y sus consecuentes efectos. Proponemos caracterizar la idea de amor en estos textos y establecer similitudes y diferencias. Para tal propósito presentaremos mínimamente cada una de las obras, consideraremos su conceptualización del amor y los modos en cómo entienden que debe regularse tal intensa pasión en el ámbito secular y el místico. De este modo, procuramos aportar un análisis que especifique algunos aspectos de las concepciones medievales del amor.
\end{abstract}

Palabras clave: Amor secular. Amor divino. Andres el Capellán. Margarita Porete. De amore. El espejo de las almas simples.

\section{ABSTRACT}

This article analyzes central aspects of the works De amore by Andrew the Chaplain and The mirror of simple souls by Marguerite Porete. These are texts that address the question of love, the one that exists between a man and a woman and between the soul and divinity, respectively. Both works were condemned for being judged heretical. Both works express love as ancess and its consequent effects. In these texts, we propose to characterize the idea of love and establish similarities and differences. For this purpose, we will present each one of the works minimally, consider their conceptualization of love, and the ways in which they understand that such intense passion must be regulated in the secular and mystical sphere. 
In this way, we try to provide an analysis that specifies some aspects of medieval conceptions of love.

Keywords: Secular love. Divine love. Andrw the Chaplain. Marguerite Porete. De amore/ The mirror of simple souls.

\section{RESUMO}

Este artigo analisa aspectos centrais das obras De amore de Andreas Capelão e $O$ espelho das almas simples de Marguerita Porete. São textos que abordam a questão do amor, aquele que existe entre o homem e a mulher e entre a alma e a divindade, respectivamente. Ambas as obras foram condenadas por serem consideradas heréticas. Ambos os trabalhos expressam o amor como um excesso e seus efeitos consequentes. Propomos caracterizar a ideia de amor nesses textos e estabelecer semelhanças e diferenças. Para tanto, apresentaremos minimamente cada uma das obras, consideraremos sua conceituação de amor e as formas pelas quais entendem que tal paixão intensa deve ser regulada na esfera secular e mística. Desta forma, tentamos fornecer uma análise que especifica alguns aspectos das concepções medievais de amor.

Palavras-chave: Amor secular. Amor divino. Andreas Capelão. Marguerita Porete. De amore. O espelho das almas simples.

\section{Introducción}

En este trabajo proponemos realizar un análisis de los modos de comprender el amor en el tratado $D e$ amore, de Andrés el Capellán, y El espejo de las almas simples, de Margarita Porete. Ambos trabajos sitúan el amor como clave en su composición textual. Ambas son obras que, a pesar de haber sido condenadas, tuvieron una gran circulación. El amor ha sido un componente esencial de la reflexión filosófica ya desde las consideraciones de Platón sobre el Eros, incluso en los presocráticos como Empédocles, quien entendía que Afrodita era uno de los poderes básicos de la naturaleza. La tarea de pensar sobre el amor se ha sostenido a lo largos de los años en la tradición occidental. ${ }^{1}$ En este escrito caracterizaremos sucintamente las obras de Andrés el Capellán y Margarita Porete, luego analizaremos la concepción acerca del amor en tales textos y cómo procuran reglar un modo de vida y conducta. El objetivo es establecer algunos puntos de contacto a la vez que las principales diferencias entre ambos. De este modo, procuramos aportar un análisis más fino y detallado entre estas concepciones medievales del amor.

\section{De amore}

Andrés el Capellán fue un clérigo que vivió entre 1150 y 1220, quien se nombra a sí mismo como capellán de la corte. ${ }^{2}$ Tuvo una relación cercana con varias mujeres como Leonor de Aquitania, María de Chanpagne, Adela de Blois, Ermengarda de Narbona y Elizabeth de Vermandois, todas vinculadas con las cortes de amor y el patronazgo y protección de poetas de la literatura cortesana. Probablemente el tratado De amore (Acerca del amor) fue escrito después de 1186, fecha de la boda de Margarita de Francia, hija de Luis VII y hermanastra de María de Champagne, ceremonia mencionada en el texto. Si bien no hay acuerdo sobre la fecha de composición de la obra, suele situarse entre 1147 y 1190 . El texto se organiza en tres libros bastante heterogéneos en su extensión y carácter. El primero trata sobre la definición del amor, la etimología del término, los efectos de tal pasión, los sujetos de la misma —entre

\footnotetext{
${ }^{1}$ No solo en la producción textual del Occidente cristiano, sino que en otras tradiciones, como en la islámica, sucede que grandes autores destinaron obras para reflexionar sobre el amor. El Islam no se presenta como una religión del amor, como el cristianismo. Sin embargo, el Dios del Islam tiene como uno de "los más bellos nombres" el de al-Wadûd, esto es, "el Amoroso, el Afectuoso, el Constante en su amor", al que se refieren dos grandes autores del Islam clásico, Algazel e Ibn Arabî de Murcia, cf. Guerrero (2008).

${ }^{2}$ Le Goff (2008: 25) entiende que el Capellán podría ser un clérigo, un proto-intelectual, sabio, profesor y pensador por oficio.
} 
otras temáticas - e incluye una serie de diálogos entre varones y mujeres de diferentes clases sociales, es el libro más extenso. El segundo se dedica a los problemas de cómo alcanzar y conservar el amor. Sobre el tercer libro se ha discutido bastante, pues resulta en cierto sentido paradójico dado que se trata de un discurso que condena el amor y presenta a la mujer como la responsable de todos los males. ${ }^{3}$

En 1277 el Papa Juan XXI escribió al obispo de París preocupado por las herejías difundidas en aquel momento. Étienne Tempier convocó una comisión de teólogos para que elaborasen un listado de tesis cuestionables, reunidas luego en el Syllabus. En el prólogo del Syllabus no se indica la fuente de las proposiciones condenadas, con una notable excepción: el De amore. La identificación de las tesis prohibidas resulta difícil y es discutida. Unas son aristotélicas, otras avicenianas, otras averroístas, algunas de autores no filosóficos, algunas incluso de Tomás de Aquino, de otras no es posible identificar la autoría. El De amore se prohibía en su totalidad y se lo unía a tratados de nigromancia. Una de las tesis condenadas en el Syllabus, la ciento setenta, "porque el pobre de fortuna no puede obrar bien en moral" (quod pauper donis fortune non potest bene agere in moralibus) ha sido puesta en relación con el segundo diálogo del texto del Capellán, una conversación entre un plebeyo y una mujer noble (Piché 1999, Denomy 1946). Ambos textos tienen una base común en tanto entienden que la pobreza es un obstáculo para ejercer la virtud o acciones nobles (De Libera 2002: 128). En la obra de Andrés, el plebeyo puede ennoblecerse mediante el trabajo para alcanzar el amor. Así, el amor tiene un valor incuestionable para la nobilitas, en tanto da valor a cualquier hombre, aun si no ha nacido en la nobleza, de ahí que se argumente sobre la "nobleza de carácter" adquirida con ayuda del amor (Andrés el Capellán, 2006: I. VI 91-93). ${ }^{4}$

Durante los siglos XII y XIII De amore circuló entre público laico y clerical. La prohibición en cierto sentido fue vana, pues el texto fue copiado y traducido en las cortes europeas. El siglo XII ha sido caracterizado como "siglo del amor". Hasta entonces, no se habían escrito tanta cantidad de tratados sobre el amor en sus diferentes concepciones y aspectos, ni tantos textos literarios acerca de dicha pasión (Singer, 1992). García Gual (1997) sostiene que la sentencia "el amor es un invento del siglo XII" (atribuida al historiador francés Charles de Seignobos) puede parecer exagerada, pero tiene sentido si se matiza y precisa. En efecto, se trata del amor cortés, de esa pasión que enaltece toda una literatura a partir de la poesía trovadoresca. ${ }^{5}$ El concepto de amor cortés (amour courtois) fue establecido por Gaston Paris (1883: 519). El amor cortés es un amor codificado: el amor es propio de la nobleza, inspira proezas, servicio y obediencia a la dama, conlleva idolatría y secreto.

\section{El espejo de las almas simples}

Margarita Porete ha sido identificada como una beguina que escribió y transmitió sus enseñanzas en los últimos años del siglo XIII. Se la suele considerar como la primera mujer quemada en la hoguera en 1310, si bien contamos con información proporcionada por otra beguina, Hadewijch de Amberes, quien en su obra Visioenenboek (Libro de las visions, ca. 1240) menciona la muerte de una beguina (Alyedis) ajusticiada por el primer inquisidor general, Robert le Brouge (Van Mierlo, 2003: 189). ${ }^{6}$ Se ha propuesto que Margarita nació entre 1250-1260 (Morino 1993: 11), si bien la información biográfica es exigua y proviene del proceso de condena (Field 2012: 209 ss). Su obra Le mirouer des âmes simples anéanties et qui seulement demeurent en vouloir et désir d'amour (El espejo de las almas simples anonadadas y que solamente moran en querer y deseo de amor) habría sido escrita un poco antes de 1290, un siglo

\footnotetext{
${ }^{3}$ Para un análisis sobre la consistencia de la obra y las distintas posiciones actuales, véase Martínez Sáez (2021: 99 ss).

${ }^{4}$ Esta idea de que la nobleza puede adquirirse por amor se relaciona con elementos de la Ética a Nicómaco que Andrés pudo conocer por las versiones árabes (Bianchi, 1990: 161-163). También el platonismo se hace presente en la poesía árabe: Ibn Zaydūn, que amó a Wallāda, hija del califa omeya al-Mustakfî, expresa que por amor un amante de baja extracción social se iguala con la mujer de quien está enamorado. Por otro parte, entre los padres de la Iglesia se aceptaba el amor como vía de ennoblecimiento interior dado que acerca el hombre a Dios. ${ }^{5}$ Suele ubicarse el nacimiento de la literatura caballeresca europea a fines del siglo XII, con los romans de Chrétien de Troyes, a lo que debemos agregar los textos de Shota Rustaveli, El caballero de la piel de tigre (escrito en lengua georgiana), y de Ibn Hazm, El collar de la paloma.

${ }^{6}$ Robert le bougre fue declarado inquisidor general del reino de Francia por una bula de Gregorio IX en 1233. Se lo llamaba "el bougre" porque antes de entrar en la orden de los dominicos había formado parte de los cátaros que popularmente se designaban burgari, "búlgaros". Al respecto, véase Sánchez Herrero (2005).
} 
después del De amore. Entre 1296 y 1306 se quema el libro en la plaza pública y se prohíbe que siga en circulación. En tales circunstancias Margarita procuró certificar la ortodoxia de su trabajo mediante tres autoridades eclesiásticas (el franciscano Juan, el cisterciense don Franco de Villiers y el maestro de París Godofredo de Fontaines), quienes aprobaron el texto, de modo que se condenó un libro aprobado (McGuinn 1998: 437, De Gier 2014: 128). ${ }^{7}$ Margarita, a pesar de la prohibición, siguió divulgando su obra, por lo que fue arrestada en 1308 y puesta a disposición del inquisidor de París. En 1309 una comisión de veintiún teólogos estudió quince proposiciones del Espejo juzgándolas heréticas (Verdeyen 1986, Field 2012). Margarita se negó a retractarse, fue condenada como hereje relapsa y quemada en la hoguera. Después de su muerte, autora y texto se separan. ${ }^{8}$

Aun cuando el libro fue prohibido sobrevivió en no menos de seis versiones en cuatro lenguas. Entre los siglos XIV y XV fue traducido al latín, italiano, inglés, y quizás a algún dialecto alemán, convirtiéndose en una de las obras místicas de mayor circulación. Se trata de un trabajo didáctico, que incorpora lenguaje y temas del amor cortés, pero mantiene un carácter más especulativo, vinculado con el lenguaje apofático y la vía negativa. Es un diálogo entre diversas personificaciones como Dama Amor, Alma, Razón, Pura Cortesía, Discernimiento. ${ }^{9}$ El libro consta de ciento cuarenta capítulos divididos en dos partes, una primera (I- CXXII) y una segunda más breve (CXXIII- CXXXIX), más el capítulo final CXL con la approbatio. Margarita despliega el camino que debe proseguir el alma para llegar a la tierra de la verdadera libertad.

\title{
Concepción del amor
}

Ambas obras se centran en el amor. En De amore se presenta una definición del amor:

\begin{abstract}
El amor es una pasión innata que nace de la visión de la belleza del otro sexo y del excesivo pensamiento por la misma, que lleva a desear, por encima de todo, la posesión de los brazos del otro, y así realizar de mutuo acuerdo todos los preceptos del amor (Andrés el Capellán, 2006: I. I 1). ${ }^{10}$
\end{abstract}

La definición establece que se trata de una pasión (passio) innata, es decir, connatural a la naturaleza humana. Esta pasión se desata por una visión. Ahora bien, el aspecto que queremos destacar es la cualidad de "pensamiento desmedido" (immoderata cogitatione). El Capellán sostiene que cuanto más se piensa en la dama más se inflama el amor, y que no basta cualquier reflexión para hacer surgir el amor, sino que debe ser una inmoderada, excesiva, desenfrenada. Esta caracterización se centra en el exceso que crea la experiencia amorosa. ${ }^{11}$ Este aspecto se señala en otras secciones de la obra. Así, en el capítulo segundo del libro I se afirma que esta atención hacia la amada es asidua (assidua), en el capítulo seis se dice que el amor comienza a crecer de forma desmesurada (immoderata suscipit incrementa). En uno de los diálogos del mismo libro, entre un hombre de alta nobleza y una plebeya, el enamorado se siente invadido por el pensamiento sobre la amada y la desea por sobre todas las cosas. En el libro III, la reprobatio amoris, se indica que el pensamiento excesivo (nimia cogitatio) debilita el cerebro produciendo enfermedades físicas. Por otra parte, todo este poder del impulso del amor podemos entenderlo en relación con el poderío del dios Amor. En el diálogo entre un varón y una dama nobles, la mujer, que no acepta acceder a los requerimientos amorosos, no comprende algunas expresiones de su enamorado. Este relata una historia en la que los séquitos del dios Amor reciben sus premios o castigos

\footnotetext{
${ }^{7} \mathrm{La}$ approbatio se conserva en las versiones latinas y del inglés medio. Se ha querido ver en Jean de Querayn, según la versión inglesa, al doctor sutil Juan Duns Escoto.

${ }^{8}$ El texto se publicó en 1927 como anónimo. Simone Weil se sintió conmovida por el Espejo y lo menciona en sus últimas obras. En 1946, Romana Guarnieri reestableció el vínculo entre texto y autora.

${ }^{9}$ Babinsky (1987: 91-92) señala que la estructura del texto se corresponde al diálogo de tradición boeciana, con figuras alegóricas que fundamentan sus concepciones en el neoplatonismo. Se mantienen las mayúsculas cuando se trata de los personajes del diálogo.

${ }^{10}$ Amor est passio quaedam innata procedens ex visione et immoderata cogitatione formae alterius sexus, ob quam aliquis super omnia cupit alterius potiri amplexibus et omnia de utriusque voluntate in ipsius amplexu amoris praecepta compleri. La traducción ha sido levemente modificada.

${ }^{11}$ La definición del amor como immoderata cogitatione por la forma del sexo opuesto puede proceder de la teoría médica de Constantino el Africano en su Pantegni y del Canon de Avicena, ambos conocedores de Aristóteles. Avicena en su Canon de medicina define al amor pasional como una forma de desorden mental causado por la meditación excesiva sobre la imagen de una mujer sexualmente inalcanzable, cf. Grunter (1930).
} 
según su comportamiento. Quienes no accedieron a servir a Amor sufren un eterno castigo sin perdón. El rey Amor rige el mundo y por eso no es aconsejable huir de él. En este mismo diálogo, el varón noble aprende de una mujer — que ha sido castigada por no entregarse al amor- las principales reglas del amor, que revisaremos en la sección siguiente. Dado que se trata de un dios que impone una conducta, descripto asimismo como rey, se habla de la milicia de amor (militia amoris), pues los enamorados batallan por cumplir su propósito. Agreguemos que en esta misma sección se habla del "rayo de amor". Hay allí una descripción sobre las mujeres que han sido o no tocadas por el rayo de amor (amoris radio), de acuerdo con su ubicación en el palacio del rey Amor. Se trata de una idea que se reitera en la obra. En el capítulo cuarto del libro I se dice que quien es amado brilla por el rayo del amor (radio fulget amoris). Como mencionamos en el primer apartado, el amor puede ennoblecer a quien no posee una nobleza determinada por la sangre. Un hombre plebeyo enamorado de una noble dice a su amada: "Tampoco establece diferencias por el nacimiento. Tan solo se fija en esto: si una persona es apta para manejar las armas del amor [...] el amor empuja a todos los hombres de cualquier clase que sea a la exaltación amorosa" (Andrés el Capellán, 2006: I. VI 71). ${ }^{12}$ La dama objeta que por su nobleza de sangre no puede acceder a tales proposiciones. Sin embargo, el hombre responde que "pareces asentir a los errores de quienes no aceptan la integridad moral si no va seguida de nobleza y de belleza, aceptando la belleza del cuerpo y la nobleza de la sangre sin la integridad moral", y agrega "no fue la belleza, ni el cultivo del cuerpo, ni aun la opulencia de cosas, sino la sola probidad de las costumbres lo que primariamente distinguió a los hombres en nobleza y aun introdujo la diferencia de clase" (Andrés el Capellán, 2016: I VI 90-91). De esta manera el amor deviene un impulso para el perfeccionamiento moral y permite alcanzar la nobilitas independientemente de la condición que se tenga por nacimiento.

Si bien la obra de Andrés está escrita en latín, la literatura del amor cortés se distingue por estar escrita en lengua vernácula, como las obras de las beguinas. El amor cortés expresa una forma de entender el amor que surgió en la literatura francesa del siglo XII, y ha sido calificado como un "sistema" de amor cortesano, un "código", un "cuerpo" de reglas y aun como una "forma de vida" (Singer, 1992: 35). De Rougemont (1993: 79 ss) popularizó la noción de que el amor cortesano era "realmente" antisexual, purista y ascético, de conformidad con su supuesta dependencia de la herejía cátara. Denomy (1947) calificó el amor cortés como herejía. La doctrina del amor cortés incluía los siguientes puntos que el autor consideraba heréticos: la apoteosis del amor humano, la concepción de que esta pasión es divina y la idea de que los vínculos sexuales fuera del matrimonio son deseables. Pero esto no solo altera la influencia de la herejía cátara, sino que también distorsiona la naturaleza de la literatura no religiosa sobre el amor en la Edad Media. En la mayor parte de ella la carencia sexual no era un principio central o básico, y hasta entre los trovadores la represión y la renuncia raras veces se identificaban con el ascetismo o la negación de los componentes sexuales del amor. El amor cortesano de la Edad Media no tenía nada que decir respecto al tipo de unidad apasionada que buscaban filósofos y místicos, pero exaltaba el valor y la conveniencia de un estado comparable que hombres y mujeres podían alcanzar en su relación mutua. Con todo, es la idea de exceso lo que entendemos puede establecerse como punto común entre el amor cortés y el amor místico, como argumentaremos más adelante.

Por otra parte, la relación entre amor cortés y cristianismo ha sido analizada (Russell, 1965: 40). La aparente similitud entre el lenguaje del amor cortés y el del misticismo cristiano no ha pasado desapercibida. La tensión del amor, la angustia de la separación, la idolatría del amado son similares en el sentimiento místico. Underhill (1961), si bien entiende que no puede identificarse el místico con el extático, señala similitudes entre el amor divino y el profano o secular, en tanto el amante devoto de la literatura cortesana como el místico, sirven sin esperanza de recompensa. ${ }^{13}$ El lenguaje del exilio y del peregrinaje son comunes a ambos. Para ser digno de su amada, el amante cortés ha de aceptar un largo camino, lleno de barreras y trampas, sin esperanza alguna de retribución, está condenado a suspirar y suplicar de lejos, porque su amada vive, a menudo, en tierra extranjera:

\footnotetext{
${ }^{12}$ Para un análisis en detalle, véase Cervera Novo (2010).

${ }^{13}$ A esta interpretación se opone Gilson (1940), quien entiende que no hay similitud alguna.
} 
Noble dama, yo no solo os pido nada, sino que me aceptéis por servidor. Yo os serviré como se sirve a un buen señor, aunque no pueda sobrevivir por ello la recompensa. Heme aquí a vuestras órdenes, sincero y humilde, alegre y cortés (Delorme, 2001: 142).

El amante tiene como fin último el servicio de su amada. Se trata del amor de lonh (amor de lejos) de los trovadores, tal como se encuentra en Jaufre Rudel. ${ }^{14}$ Cirlot (1996) entiende que el amor de lonh en relación con la distancia conlleva el exceso del pensamiento, pues "la lejanía es la causa de que el amante se abandone al pensamiento". Aquí reencontramos esa idea del pensamiento desmesurado de la definición de amor del De amore. El debate de los trovadores a lo largo del siglo XII acerca del amor de lonh gira fundamentalmente sobre el pensar excesivo que genera, de modo que incluso interesa más el hecho de que el amor de lonh sea un amor per cuda (amor por pensamiento) que un amor ses vezer (amor sin ver) (García Acuña, 2009: 33).

Las ideas que hemos revisado del De amore tienen sus puntos de similitud con algunas del Espejo. Margarita establece una analogía entre el amor de un hombre y una mujer y el amor del alma y Dios. El texto comienza con unas palabras de Amor que relata un ejemplo de amor humano aplicable al amor divino:

\begin{abstract}
Ejemplo. Hubo una vez una doncella, hija de rey, de gran corazón y nobleza, así como de gran coraje, que vivía en un país extranjero. Sucedió que la doncella oyó hablar de la gran cortesía y nobleza del rey Alejandro y al instante su voluntad lo amó por el gran renombre de su gentileza. Pero estaba tan lejos esta doncella del gran señor al que había entregado su propio amor que no podía ni verlo ni tenerlo; por eso a menudo se sentía desconsolada, pues ningún otro amor le bastaba más que este. Y cuando vio que este lejano amor estando tan cercano o dentro mismo de ella estaba a la vez tan lejos fuera de ella, pensó que encontraría consuelo a su desazón imaginando una figura de su amigo por quien a menudo sentía su corazón herido. Entonces hizo pintar una imagen que representaba el rostro del rey que amaba lo más cercana posible al modo en que ella le amaba y a la medida del amor que la tenía presa, y por medio de esta imagen y con otros métodos suyos soñó al propio rey (Margartia Porete, 2005: I, trad. levemente modificada).
\end{abstract}

Este ejemplo mundano representa lo que sucede con el alma amante de la divinidad. Margarita comienza su texto con esa referencia a un país extranjero (patria aliena) en el que habita el rey del que la doncella se enamora. El amor es caracterizado como lejano y cercano a la vez, describiendo así la particular topología de la experiencia amorosa. Luego el Alma realiza la analogía entre el episodio relatado y lo que le sucede a ella misma. El Alma escuchó hablar de un rey. Este rey es Dios, quien entrega el libro al Alma: ambos son los autores de la obra. En el prólogo del Espejo, el tema de l'amour du monde o cortesano, el amor secular, es explícito. El texto de Margarita es un ejemplo de este género como una forma literaria completamente desarrollada, pero con raíces en el siglo XII, relacionadas en parte con la alegoría de la novia/ novio de los sermones de Bernardo de Claraval sobre el Cantar de los Cantares y la influencia cisterciense en general con el gran desarrollo de la mística nupcial, así como con el medio teológico en el que el amor afectivo fue prominente. ${ }^{15}$ A lo largo del Espejo, Margarita desarrolla imágenes cortesanas mediante el uso de conceptos como cortesía, generosidad, amor distante, nobleza, monarquía, dones de la amada y el éxtasis de la unión amorosa. En los textos de las beguinas el lenguaje del amor cortés se fusiona con la expresión metafísica del amor a Dios. Ahora bien, si bien la Minnemystik (mística nupcial) fue característica del movimiento de las beguinas, no debemos olvidar otra forma de comprender sus pensamientos, particularmente importante en Margarita: la Wesenmystik (mística de la esencia), que se caracteriza por un pensamiento más especulativo. ${ }^{16}$

\footnotetext{
${ }_{14}$ Para la obra de Jaufre Rudel, véase Riquer (1975: 148-169), Cirlot (1996).

15 Tanto los cistercienses como los victorinos desarrollaron una mística del amor. Queremos destacar la figura de Guilermo de Saint Thierry en tanto fue el teólogo del siglo XII "más griego", en el sentido de recuperar a Orígenes — primer autor de un Comentario al Cantar de los Cantares, al que interpreta simbólicamente - y los padres alejandrinos, olvidados en Occidente, con la excepción, claro, de Eriúgena.

${ }^{16}$ Las tres grandes beguinas del siglo XIII - Hadewijch de Amberes, Matilde de Magdeburgo y Margarita Porete- emplearon lenguaje del amor cortés, pero con significativas diferencias. Hadewijch y Matilde se basaron en buena parte en la imaginería sensorial, mientras Margarita casi no emplea esos recursos, sino aspectos más conceptuales, como la nobleza del alma, algo que, por otra parte, tiene una clara referencia escritural, cf. Lucas 19.12, Meister Eckhart, Liber Benecdictus II Von dem edien menschen (Del hombre noble).
} 
Hemos destacado la dimensión del exceso en el amor cortesano. En relación con la experiencia mística, seguimos a de Certeau (2008: 294) quien entiende que "es místico aquel o aquella que no puede parar de caminar y que, con la certidumbre de lo que le falta, sabe, de cada lugar y de cada objeto, que no es eso, que uno no puede residir aquí ni contentarse con esto. El deseo crea un exceso. Excede, para y pierde los lugares". En el Espejo este exceso aparece de diversos modos. Es Amor quien enseña al Alma el camino de la unión con la divinidad, que es asimismo el camino de la libertad. Amor explica:

Esta Alma - dice Amor - ha entrado en la abundancia y las afluencias del divino Amor, no por haber alcanzado el conocimiento divino, pues no puede darse que un entendimiento por iluminado que sea pueda alcanzar ninguna de las afluencias de divino Amor. Pero el amor de esta Alma es tan afín al afluir del 'más' de este Amor más que divino (no por haber alcanzado el Entendimiento de Amor, sino por haber alcanzado su exceso de amor) que la ornan los ornamentos del exceso de paz en la que vive y dura, es, fue y será sin ser (Margartia Porete, 2005: LII).

De este modo, por efecto de la presencia de Amor, el alma se encuentra en un estado de abundancia que la ubica más allá del ser. Ese amor que fluye es un "más", pues es un amor más que divino en tanto exceso que supera lo que se alcanza por vía del entendimiento humano. El alma goza de no poder captar nunca toda la riqueza de su amado, sino de participar de él de una forma que podemos denominar "negativa". Es decir, hay conocimiento en el desconocimiento. ${ }^{17}$ Esto transforma el alma que es un ser sin ser. El alma se entrega por completo a la voluntad de Dios y no quiere otra cosa "no deja entrar en su pensamiento nada que sea contrario a Dios" porque solo piensa en él (Margarita Porete, 2005: XI).

Y aquí encontramos un rasgo diferencial entre este amor místico y el amor cortés. En la experiencia mística, este exceso del pensamiento por el amor a la divinidad deviene en un no pensar: "no busca a Dios por la penitencia, ni a través de ningún sacramento de la Santa Iglesia, ni por pensamientos, palabras u obras, ni a través de criatura terrestre ni celeste, ni por justicia o misericordia, ni por gloria de la gloria, ni por conocimiento divino, ni por divino amor, ni divino loor" (Margarita Porete, 2005: LXXXV). Es decir que en la experiencia mística el exceso de pensamiento, que es un exceso de amor, se transforma en un más allá del pensamiento y del amor. Cuando Margarita describe su búsqueda, explica haber buscado a Dios en las criaturas pero no lo encuentra allí, entonces "se puso a pensar, y su pensamiento le dijo que fuera a buscar lo que reclamaba en el fondo nodal del entendimiento de la pureza de su supremo pensar" (Margarita Porete, 2005: XCVI). Este más allá del pensamiento puede ser asimilado a ese fondo del pensar desde el que se produce la escritura de la obra para la propia transformación y la de quienes lean el texto. La transformación del alma se describe en un trayecto de siete estados. En el cuarto el alma es arrebatada por la supremacía de amor en el deleite del pensamiento en meditación. Ahí el Alma es tan vulnerable, noble y deliciosa que no puede sufrir que nadie la toque sino el toque del puro deleite de Amor, y se encuentra orgullosa por la abundancia de amor (Margarita Porete, 2005: CXVIII). Estas almas aman "sin un porqué" (Margarita Porete, 2005: XLIX). En el Espejo, la diferenciación entre el noble y el villano se expresa mediante las almas desinteresadas "que sublime Amor demanda" y las almas interesadas que son aquellas que se mantienen sometidas al ejercicio de las virtudes (Margarita Porete, 2005: XLIX). En este proceso de transformación, producido por el exceso de amor y pensamiento, el "Alma mora en la pura nada sin pensamiento" (Margarita Porete, 2005: XCVII). De este modo se trata de un más allá del pensamiento y del amor. Un capítulo se titula justamente así: Razón pregunta qué hacen aquellos cuyo estado está por encima de sus pensamientos. Se trata de un diálogo entre Razón y Amor:

[Razón:] ¡Ah, por Dios! — dice Razón—, ¿qué hacen aquellos cuyo estado está por encima de sus pensamientos?

Amor: Se embelesan en aquel que está en la cima de la montaña y se embelesan por igual en aquel mismo que está en el fondo de su valle en un nada pensar que se encuentra encerrado y sellado en la secreta clausura de la suprema pureza de tan excelente Alma; clausura que nadie puede abrir, ni desellar, ni cerrar cuando

\footnotetext{
${ }^{17}$ Se trata de la diferencia establecida por el neoplatonismo, especialmente Proclo y Dionisio, entre el Dios absolutamente trascendente y el Dios participado.
} 
está abierta, si el gentil Lejos-cerca, de muy lejos y de muy cerca, no la abre o cierra; él es el único que tiene las llaves, no hay otro que las lleve, ni las podría llevar (Margarita Porete, 2005: XCVIII).

Aquellos que habitan en la cima de la montaña y están embelesados (ilz s'esbayssent, ipsi stupent) no piensan en nada (nient penser, nichil cogitare). Aquí se incluye una referencia al gentil Lejoscerca (gentil Esclar, nobile longe), que es una de las maneras de denominar a la divinidad, que trae aparejadas nociones del amor cortés y la idea del amor de lejos. En primer lugar, Lejoscerca es nombrado como gentil (nobile) lo que nos evoca aquella idea sobre la nobilitas en el amor cortés, es decir, el amor tiene que ver con la nobleza del alma, pues esta es creada a imagen de la divinidad. En efecto, un capítulo se titula Cómo esta Alma lleva la impronta de Dios como la cera de un sello: "Esta Alma lleva la impronta de Dios y tiene en la unión de amor su verdadero cuño, a la manera de la cera que toma la forma del sello, así toma esta Alma la impronta del ejemplar verdadero" (Margarita Porete, 2005: L). ${ }^{18}$

En segundo lugar, la lejanía es explícitamente mencionada mediante la paradojal expresión que coordina lejanía-cercanía, nombrado en la literatura amor de lonh. En tercer término, la idea del rayo de amor del De amore encuentra aquí una nueva formulación porque el Lejoscerca aparece como un relámpago. Ahora bien, aquí el relámpago implica el anonadamiento o aniquilación de la propia alma. ${ }^{19} \mathrm{El}$ Relámpago opera un anonadamiento en el alma (Margarita Porete, 2005: LIX).

Una última referencia a la consideración sobre el tipo de amor del que habla el Espejo. Sobre el final de la obra, Margarita explica que se trata del retorno del alma al ser primigenio, de modo que ha dejado tres y ha hecho de dos uno, es decir, las tres potencialidades del alma y las tres personas de la Trinidad han sido superadas del mismo modo que la duplicidad del alma y la divinidad, pues se han convertido en una unidad, en una relación sin mediación. Esa unidad existe cuando el alma regresa a la simple deidad que es un ser simple "de desbordante fruición, en pleno saber, sin sentimiento, por encima del pensamiento" (Margarita Porete, 2005: CXXXVIII). Ese simple ser cumple en el Alma por caridad (caritas) cuanto el Alma cumple: "Y ese simple querer, que es querer divino, lleva al Alma a estado divino: más arriba no se puede ascender, ni más profundo descender, ni se puede estar más desnudo" (Margarita Porete, 2005: CXXXVIII). Es decir, hay una identificación entre el alma y la divinidad, de modo de producir una unión que puede ser calificada también como fusión. El alma alcanza el estado divino, que es a la vez un estado de desnudez y simpleza. ${ }^{20}$

\section{Las reglas de amor}

Ahora bien, estos tipos de amor, cortés y místico, tienen una expresión "normativa" en el establecimiento de ciertas reglas que procuran regular o guiar la conducta a fin de alcanzar el objetivo buscado: el encuentro amoroso. Como revisamos en la primera sección, se ha pensado el amor cortés como un amor codificado que establece un cierto modo de vida. Si bien el capítulo ocho del libro II de amore se titula Sobre las reglas del amor y elabora una lista de treinta y una reglas que entrega el rey del Amor, aquí vamos a evaluar otra sección: las doce reglas del libro I enmarcadas en el diálogo de un varón y una dama nobles. El noble relata el itinerario del dios Amor. Este noble había perdido a su señor en un paseo, y encontró a una dama que era castigada por no haber cumplido con los requerimientos del amor en la vida terrena. Ella le enseña al noble cuáles son estas reglas:

\footnotetext{
${ }^{18}$ Esta misma idea en Eckhart, $D W$ II $P r .50$.

${ }^{19}$ Espejo LIX: “Al comienzo esta Alma vivió la vida de la gracia, que ha nacido en la muerte del pecado. Después vivió la vida del espíritu, que ha nacido en la muerte de la naturaleza; y ahora vive de la vida divina, que ha nacido de la muerte del espíritu. Esta Alma que vive vida divina, está siempre privada de sí misma [...] cuando no está en ninguna parte por voluntad propia, ni en Dios ni en ella misma, ni en su prójimo, sino en el anonadamiento o aniquiliación que este relámpago opera en ella". Sobre el relámpago, 2 Cor. 12. 2-4.

${ }^{20}$ Justamente por esta característica entendemos que se puede cuestionar la interpretación de Rousselot (1981) del amor místico como un amor dual. El autor diferencia entre amor físico, de acuerdo con la teorización de Tomás de Aquino, y amor místico, representado por diversos autores - no mencionan a ninguna mística mujer- que basan su teorización del amor en una absoluta trascendencia. La auténtica intención de Rousselot era introducir a Dios como aquel del cual procede todo el dinamismo amoroso. Le importaba precisamente que el origen del mismo no proviene desde fuera, exclusivamente como Amado, sino desde dentro a modo de Amante que ama en el mismo hombre.
} 
I. Huye de la avaricia como de una peste maligna y abraza su contrario

II. Mantente casto para tu amada

III. No quieras destruir a sabiendas el amor de una mujer unida rectamente a otro

IV. No pretendas el amor de una mujer con la que te impide casarte un sentimiento natural de vergüenza

V. Acuérdate de evitar todo tipo de engaño

VI. No quieras tener muchos confidentes de tu amor

VII. Trata de permanecer siempre fiel al ejército del amor, obedeciendo las órdenes de sus damas

VIII. Has de mantener siempre el pudor al dar y recibir las compensaciones del amor

IX. No debes ser maldiciente

X. No propales los secretos de los amantes

XI. Muéstrate educado y cortés en todas las cosas

XII. No excedas los deseos de tu amante cuando te entregues a los placeres del amor (Andrés el Capellán, 2006: I. VI 268-269).

Walsh (1982) señala que los doce preceptos del amor en este diálogo trasponen el ideal del amor secular en amor cristiano, en tanto se establecen reglas que prescriben generosidad, castidad y fidelidad, entre otras. Por nuestra parte, y en consonancia con la lectura de Martínez Sáez (2021: 183), entendemos que si la propia definición de amor expresa que se trata de una pasión inmoderada, resulta lógico pensar en una serie de reglas que ayuden a lidiar con los excesos del amor. Estas reglas procuran indicar de qué modo el amante puede adquirir un dominio de sí que posibilite alcanzar su anhelado objeto. Con todo, no es un dato ocioso que las reglas provienen directamente del dios Amor, pues de esta manera se caracterizan como trascendentes, y esto las liga a los mandamientos cristianos, en otro de los puntos que podemos establecer un paralelismo entre ambos tipos de amor. Claro que en este caso, se trata de reglas que permiten que el amante alcance el amor mundano y terrenal en este mundo.

Ahora bien, en la obra de Margarita no hay una reglamentación similar, aun así consideramos oportuno revisar un texto anónimo que contiene una serie de reglas de amor para las beguinas. ${ }^{21}$ Se trata de Règle dês fins amans (Regla de los auténticos amantes). ${ }^{22}$ A pesar de que el movimiento de las beguinas terminó prohibido por el Concilio de Viennes de 1311 — concilio establecido luego de la muerte de Margarita-, con anterioridad las autoridades eclesiásticas habían aprobado esta forma de vida en común. Entre 1231 y 1233, el papa Gregorio XI dirigió varias bulas de protección hacia las beguinas, aceptando su forma de vida comunitaria bajo la dirección de una maestra que ellas mismas podían elegir. Carecemos de fuentes que informen adecuadamente sobre este estilo de vida, si bien compartimos aquí un relato que nos permite introducirnos en las reglas de las beguinas:

Había un maestro de París que llamó a un compañero y le pidió que le trajera a una beguina, y este le trajo una. El maestro le dijo: ‘¿Qué [tipo de] gente sois y qué hacéis?'. 'Maestro — contestó ella— -...] sabemos amar a Dios, confesar, guardarnos [del mal], conocer a Dios, los siete sacramentos, podemos amar y discernir los vicios de las virtudes, tener humildad sin orgullo, amor sin odio, paciencia en tribulación, claro conocimiento de Dios y de la santa Iglesia, y estamos preparadas para sufrir todo por Dios: todo esto es ser beguina (beghinages)'. Cuando el Maestro lo escuchó, se dijo: 'Entonces sabéis más de divinidad que todos los maestros de París' (Bara Bancel, 2016: 67).

\footnotetext{
${ }^{21}$ Margarita hace referencia a una regla en su texto. Se trata de la segunda parte del Espejo, CXXXVII: " $<$ Esta Alma es profesa en su propia religión y ha guardado su regla. ¿Cuál es su regla? Ciertamente disolverse por anonadamiento en el estado primigenio en que la recibió Amor. Ha pasado su examen de probación y ha librado todas las batallas contra todas las potencias. Pero aquella última de la que hemos hablado fue especialmente dura. Y no es maravilla. No hay guerra más penosa que la guerra de los amantes: la que los mata debe pasar por el filo de la espada. Ahí le es arrebatado todo su poder sin poderlo recuperar y queda sanada de toda enfermedad. ¡Oh, qué> gran piedad esta masacre de amantes que ayudaron al Alma a vencer a sus enemigos y que, al final, todos han muerto! ¿Qué tiene ello de maravilloso? Dios dispensa sus bienes como le corresponde y por ello esta Alma ya no quiere estar en ese lugar. Su imaginar sobrepasó en un tiempo lo imaginable poniéndola a ella en el lugar de Dios, pero era porque estaba fuera de su ser". La sección demarcada entre corchetes angulares aparece solo en la versión latina.

${ }^{22}$ Seguimos aquí las investigaciones de Bara Bancel (2016), a quien agradecemos facilitarnos el texto. Fue transcrito y publicado por Karl Christ en 1927. La règle des fins amans consta de catorce páginas.
} 
Tal como hemos comprobado, en la obra de Margarita el amor tiene un rol central, en tanto dinamiza el proceso de transformación e incluso lleva a un más allá del amor. En esta cita, la anónima beguina menciona en primer término su amor a Dios, aspecto central en la Regla de los auténticos amantes. Se trata del texto medieval más extenso acerca de la forma de vida beguina, que no pretende tanto legislar, sino más bien articular los ideales de la comunidad. Fue redactado en francés antiguo, por un autor o autora anónima a finales del siglo XIII, hacia 1300, de modo que es un texto contemporáneo a la obra de Margarita. Quien escribió la Regla estaba familiarizado con la literatura cortesana y también con la Escritura y los padres de la Iglesia. ${ }^{23}$ La autora podría haber sido una beguina, pues muchas de ellas poseían una profunda formación teológica y experiencial. Según Ruh (2002: 379-380), la Regla muestra una afinidad con Margarita, tanto por su contenido como por la forma de expresión, aunque con una menor radicalidad. Esta regla se detiene especialmente en la actitud interior y el significado espiritual de ser beguina, verdadera amante de Cristo, a la vez que muestra cómo entendían las beguinas su estilo de vida como religiosas de la Orden de los auténticos amantes. ${ }^{24}$

La Regla define como "auténtico amante (fin amant) a aquel o aquella que ama a Dios con autenticidad (finement) [...] Es decir, puramente, y de todo corazón y con todas nuestras fuerzas y con toda nuestra virtud [...] Así nos amó él” (Bara Bancel, 2016: 70). La Regla establece doce signos por los cuales se pueden conocer a los verdaderos amantes:

I. Odiar aquello que odia su Amigo: el pecado

II. Guardar los mandamientos de su Amigo

III. Descubrir con frecuencia el corazón a su Amigo

IV. Amar lealmente

V. Pensar con frecuencia y atentamente en su Amigo

VI. Escuchar con gusto la palabra de su Amigo

VII. Pedir atentamente noticias de su Amigo

VIII. Ir frecuentemente y de buen grado allí donde se encuentra su Amigo

IX. Enviar con frecuencia joyas y bellos dones a su Amigo

$\mathrm{X}$. Recibir devotamente las joyas que su Amigo envía: y estas son pobrezas, privaciones, enfermedades y tribulaciones

XI. Dolerse por la desgracia de su Amigo

XII. Estar dispuestos a hacer todo aquello que quiere y manda el Amigo, con [todo] corazón, cuerpo y haber (Bara Bancel, 2016: 71).

De acuerdo con la Regla, las beguinas poseen estos signos más verdadera y espiritualmente, pues pertenecen a la Orden de los amantes, como Magdalena, la amada y amante de Cristo. Dado que cumplen con estas reglas, ellas recibirán doce alegrías que Dios entrega, entre ellas llegar a ser amigas íntimas de Cristo, recibir sus visitas, etc. Se saben herederas del reino de Dios, con la certeza de su amor, porque aman a Dios. La Regla aporta una etimología de "beguina", que viene del latín benigne (benignae), esto es, "buen fuego", porque ellas son esos fuegos buenos que iluminan a los que están lejos.

Si bien las reglas del De amore y la Regla de los auténticos amantes no son totalmente equiparables, nos interesa señalar algunos paralelos. La Regla establece en primer lugar alejarse del pecado, algo que podemos encontrar de algún modo significado en el texto del Capellán en los preceptos I y IX, referidos a la avaricia y el maldecir, ambos pecados. ${ }^{25}$ La segunda proposición de la Regla indica guardar los mandamientos que podemos asociar con la séptima regla de Andrés que señala la necesidad de permanecer fiel al ejército del amor, asimismo vinculada con el enunciado XII de la Regla que proclama hacer todo lo que indica el Amigo. El cuarto enunciado de la Regla expresa la necesidad de un amor leal. Andrés también habla sobre esto en su obra y lo traspone como regla; aquí podemos agrupar tres

\footnotetext{
${ }^{23}$ En la Regla se menciona a Jerónimo, Bernardo, Gregorio, Agustín e Isidoro. Hay alusiones a los evangelios, a Pablo, Salomón, David, Juan evangelista, y a figuras femeninas: la Magdalena, que amó ardientemente a Jesús, y la virgen María.

${ }^{24}$ En dos ocasiones se dice explícitamente: "La orden de los auténticos amantes es ser beguina" (Li ordres des fins amans est beginaiges).

${ }^{25}$ Sobre la avaricia, véase I Tim. 3.3, 6.9, Eclesiastés 5.10, Lucas 12.15. En relación con el maldecir, Santiago 3.9-11, Romanos 12.14.
} 
preceptos del Capellán: la necesidad de mantenerse casto para la amada, no buscar la mujer de otro ni pretender el amor de alguien que no lo permite la verguënza, a la vez que evitar el engaño (II-V). ${ }^{26}$ También podemos establecer un paralelo entre las sentencias VIII de Andrés y X de la Regla, pues ambas indican cómo recibir los dones que otorga el amado. En definitiva, ambas reglas procuran indicar cómo se debe cuidar la conducta para con quien se ama. En ambas se trata de amar a una figura que excede la del amante: en el caso del amor cortés por la idealización de la amada, en el caso del amor místico por tratarse de la divinidad. ${ }^{27}$

Por otra parte, el hecho de que exista una regla formulada nos hace pensar en la dimensión común y comunitaria que estos movimientos de alguna manera implicaban, aunque no se explicite completamente. Hemos mencionado la cuestión de la nobleza en ambas obras, la de Andrés y la de Margarita. En De amore hay un explícito desarrollo que diferencia la nobleza de la condición social heredada y la vinculada con las posibilidades de crecimiento moral que el amor permite. En la obra de Margarita en general se ha interpretado un cierto elitismo, en tanto se afirma en varias oportunidades que la experiencia mística de amor entre el alma y la divinidad no es acequible para cualquiera, a la vez que se habla de la soledad del alma en tal experiencia. Ahora bien, también el Espejo incluye referencias que nos permiten articular algo relacionado con una comunidad de almas. En uno de los capítulos del Espejo (XXII Cómo esta Alma es comparada al águila y cómo se despide de Naturaleza), Margarita explica que el alma se despide de la naturaleza porque Amor está junto a ella y la libera. Luego explica que el alma no necesita consuelo, no la aflige la tentación, y agrega que "es común a todos por la generosidad de caridad pura y no pide nada a nadie por la nobleza de la cortesía de bondad pura de la que Dios la ha colmado" (Margarita Porete, 2005: XXII). De manera que el alma noble es al mismo tiempo excepcional y común, y esta última característica permite pensar no solo en lo común que pueda tener con otras almas sino en una comunidad de almas. Unos capítulos más adelante, Margarita habla de las almas que están en la recta libertad del puro Amor. Allí las almas en el camino de la libertad que posibilita Amor se describen como sin sentimientos, sin apegos espirituales -pues estas prácticas se convertirían en métodos de esclavización de las almas- y permanecen en la paz de la libertad a la que "pocos se abandonan [...] y llevan en paz las disposiciones de Amor" (Margarita Porete, 2005: XXIV). Estas almas son "únicas en todo y comunes en todo" (Margarita Porete, 2005: XXIV). Esta idea se repite, dado que se afirma que un alma que arde en el fuego de la hoguera de Amor se ha convertido en el propio fuego pues Amor la ha transformado. Si bien es un fuego que arde por sí mismo y se alimenta por sí mismo, el capítulo finaliza con una referencia a lo común: "Pues un Alma así no posee en ella materia que le impida ver claro, dado que se halla sola en sí misma en virtud de la verdadera humildad; es común a todos por su generosidad y caridad perfectas y se halla sola en Dios por la divina empresa de Amor Puro". A estas consideraciones debemos sumar las referencias a los que habitan en la montaña, que son nombrados en plural. ${ }^{28}$ De este modo, las reglas que codifican y guían las conductas constituyen no solo un posible ordenamiento a seguir en la búsqueda del amor - mundano o divino - sino también cierta consideración de conciencia común, conciencia de una comunidad a la que se pertence.

\section{Conclusiones}

Durante la Edad Media, tanto en la literatura secular como en la cristiana se desplegó una gran reflexión sobre el amor. La literatura secular, en la que podemos incluir al De amore, reflexionó sobre las relaciones amorosas entre hombres y mujeres, la naturaleza de esa pasión y los modos en que debía regularse. En la cultura europea hay una inflexión en el sentimiento del amor en los escritos de los pensadores de la Iglesia en el marco de la meditación sobre las relaciones afectiva entre el Creador y las criaturas. Esta temática fue radicalizada en el pensamiento de las beguinas, en particular en Margarita Porete, la más especulativa de las místicas. Ambas corrientes de pensamiento - la del amor mundano y la del divino - fueron lectoras de textos del clasicismo latino, como Ovidio y Cicerón, este último en su

\footnotetext{
${ }^{26}$ Sobre la fidelidad, I Cor. 7.2, Mat. 5.27-28

${ }^{27}$ Una comparación de las reglas de De amore con la Benedictina en Schoeck (1951). Por otra parte, Newman (2002: 109) estrecha lazos entre la Regla y Margarita hasta el punto de sugerir que aquella sea una fuente de la gran mística.

${ }^{28}$ Cf. Margarita Porete, 2005: LIII, LIV, LXXIV.
} 
modelo de la amicitia, aporto la idea de esta pasión como un impulso voluntario fuera de sí, olvidadiza de sí, desinteresado y que conduce mediante un progreso, una depuración gradual, a la fusión con el otro (Duby, 1992). Hemos establecido algunos puntos de contacto entre la consideración secular del amor, representada aquí por Andrés el Capellán, y la conceptualización mística, según la obra de Margarita, especialmente la idea de que el amor implica un exceso de pensamiento, un exceso de experiencia, la experiencia de un exceso. Pero también pudimos establecer diferencias. Creemos que la principal distinción equiparase a los términos en los que se han clasificado, dentro del marco Cristiano, las dos grandes conceptualizaciones sobre el amor. En efecto, amar en la escuela greco-tomista es buscar el bien propio, por tanto, encontrar la propia alma, que puede equiparase al alma amada, es decir, amar es encontrar lo que se ama. En la escuela místico-extática, amar es perder la propia alma.

\section{Referencias}

Andrés el Capellán. (2014). El arte de amar honradamente. Trad. Gil Soler. P. Libros en Red.

Andrés el Capellán. (2006). Libro del amor cortés. Trad. Rodríguez Santidirán. P. Alianza. Madrid.

Babinsky, E. (1987). "The use of courtly language in Les mirouer dês simples ames Anienties by Marguerite Porete.” Essays in Medieval Studies. 4. 91-106.

Bara Bancel, S. (2016). "Las beguinas y su 'Regla de los auténticos amantes' (Règle dês fins amans)". Mujeres, mística y política. La experiencia de Dios que implica y complica. Col. Aletheia 11. Editorial Verbo Divino. Estella.

Bianchi, L. (1990). Il vescovo e i filosofi: la condamna parigina del 1277 a l'evoluzione dell' aristotelismo scolastico. Lubrina. Bergama

Certeau, M. de (2008). La fábula mística. Siruela. Madrid.

Cervera Novo, V. (2010). "Sobre las fuentes de la condena de 1277. La nobilitas en el libro De amore de Andreas Capellanus y en los tratados éticos del aristotelismo radical". Patristica Et Medicevalia. 31. 82-89.

Cirlot, V. (1996). Les cançons de l'amor de lluny de Jaufré Rudel. Columna. Barcelona.

De Gier, I. (2014). “Text as Authority: Marguerite Porete's Mirouer des simples ames.” Mulieres religiosae. Shaping Female Spiritual Authority in the Medieval and Early Modern Periods. 127-150. Brepols. Turnhout.

De Libera, A. (2000). Pensar en la Edad Media. Anthropos. Barcelona.

Deelorme: (2001). Histoire des Reines de France: Aliénor D’Aquitaine, Épouse de Louis VII, mère de Richard Coeur de Lin. Pygmalion. Paris.

Denomy, A. (1946). "The 'De amore' of Andreas Capellanus and the Condemnation of 1277. Mediaeval Studies. 8. 107-149.

Denomy, A. (1947). The Heresy of Courtly Love. Candlemass Lectures on Christian Lietature. New York.

Duby, G. (1992). El amor en la Edad Media y otros ensayos. Alianza. Madrid.

Field, S. (2012). The Beguine, the Angel, and the Inquisitor: The Trials of Marguerite Porete and Guiard of Cressonessart. University of Notre Dame Press. Notre Dame. 
García Acuña: (2009). Poética de la visibilidad del Mirouer des simples ames de Marguerite Porete. Tesis Doctoral UPF Universitat Pompeu Favra. Barcelona.

García Gual, C. (1997). El redescubrimiento de la sensibilidad en el siglo XII. Akal. Madrid.

Gilson, E. (1940). The Mystical Theology of Saint Bernard. Cistercian Studies. London.

Grunter, O. (1930). A Treatise on the Canon of Medicine of Avicenna Incorporating a Translation of the First Book. Luzac. London.

Guerrero, R. (2008). “Avicena: sobre el amor”. Anales del Seminario de Historia de la Filosofía. 25. 245-261.

Le Goff, J. (2008). Los intelectuales en la Edad Media. Gedisa. Barcelona.

Margarita Porete. (2005). El espejo de las almas simples. Trad. Garí, B. Siruela. Barcelona.

Marguerite Porete. (1986). Le Mirouer des Simples Ames. Ed. Guarnieri, R. Brepols. Turnhout.

Margaretae Porete. (1986). Speculum Simplicium Animarum. Ed. Verdeyen: Brepols. Corpus Christianorum LXIX. Turhhout.

Martínez Sáez, N. (2021). Andrés el Capellán. Dialéctica y juego en el amor. Tesis de Doctorado. Universidad Nacional de La Plata.

McGuinn, B. (1998). The Flowering of Mysticism. Men and Women in the New Mysticism. Vol. III. The Presence of God: A History of Western Christian Mysticism. Crossroad Publishing Company. New York.

Morino, A. (1995). "Introduzione." Lo specchio delle anime semplice by Margarite Porete. Sellerio. Palermo.

Newman, B. (2002). "The Mirror and The Rose: Marguerite Porete's Encounter with the dieu d'amours. The Vernacular Spirit: Essays on Medieval Religious Literature. 105-123. Palgrave. New York.

Paris, G. (1883). “L’Amour courtois.” Romania. XII. 459-534.

Piché, D. (1999). La condemnation parisienne de 1277. Coll. Sic et Non. Vrin. Paris.

Riquer, M. (1975). Los trovadores: historia literaria y textos, vol. I. Planeta. Buenos Aires.

Rougemont, D. de (1993). Amor y Occidente. FCE. Buenos Aires.

Rousselot: (1981). El problema del amor en la Edad Media. Vrin. Paris.

Ruh, K. (2002). Storia della mistica occidentale, vol. 2: Mistica femminile e mistica francescana delle origini. Vita e Pensiero. Milano.

Russell, J. (1965). “Courtly Love as Religious Dissent.” The Catholic Historical Review. 51. 31-44.

Sánchez Herrero, J. (2005). "Los orígenes de la inquisición medieval”. Clio \& Crimen. 2. 17-52.

Shoeck, R. (1951). “Andreas Capellanus and St. Bernard of Clairvaux.” Modern Language Notes. 66. 295-300.

Singer, I. (1992). La naturaleza del amor. Siglo XXI. México. 
Trojel, E. (1892). Andreae Capellani. De amore libri tres. Libraria Gadiana. Havniae.

Underhill, E. (1961). Mysticism: a study in the nature and development of man's spiritual consciousness. Dutton. New York.

Van Mierlo, J. (1925 [2003]). Hadewijch. Visioenen. Vlaamsche Boekenhalle. Antwerpen/Gent/Mechelen.

Verdeyen: (1986). "Le procès d'Inquisition contre Marguerite Porete et Guiard de Cressonessart (13091310)”. Revue d'historie ecclésiastique. 81. 48-94.

Walsh: (1982). Andreas Capellanus. On love. Duckworth. London. 